\title{
Exacerbations of COPD
}

\author{
Christian Viniol and Claus F. Vogelmeier \\ Number 3 in the Series "Acute exacerbations in pulmonary medicine" \\ Edited by Michael Kreuter and Vincent Cottin
}

\begin{abstract}
Affiliation: Dept of Medicine, Pulmonary and Critical Care Medicine, University Medical Centre Giessen and Marburg, Philipps-Universität Marburg, Member of the German Centre for Lung Research (DZL), Marburg, Germany.

Correspondence: Christian Viniol, University Medical Centre Giessen and Marburg, Philipps-Universität Marburg - Dept of Medicine, Pulmonary and Critical Care Medicine Baldingerstr. 1, Marburg 35043, Germany. E-mail: Christian.Viniolamed.uni-marburg.de
\end{abstract}

@ERSpublications

This article highlights the importance of preventing exacerbations of COPD http://ow.ly/ODQp30i5Cel

Cite this article as: Viniol C, Vogelmeier CF. Exacerbations of COPD. Eur Respir Rev 2018; 27: 170103 [https://doi.org/10.1183/16000617.0103-2017].

ABSTRACT Chronic obstructive pulmonary disease (COPD) is the third leading cause of death worldwide. While COPD is a mainly chronic disease, a substantial number of patients suffer from exacerbations. Severe exacerbations are related to a significantly worse survival outcome. This review summarises the current knowledge on the different aspects of COPD exacerbations. The impact of risk factors and triggers such as smoking, severe airflow limitation, bronchiectasis, bacterial and viral infections and comorbidities is discussed. More severe exacerbations should be treated with $\beta$-agonists and anticholinergics as well as systemic corticosteroids. Antibiotic therapy should only be given to patients with presumed bacterial infection. Noninvasive ventilation is indicated in patients with respiratory failure. Smoking cessation is key to prevent further COPD exacerbations. Other aspects include choice of pharmacotherapy, including bronchodilators, inhaled corticosteroids, phosphodiesterase-4 inhibitors, longterm antibiotics and mucolytics. Better education and self-management as well as increased physical activity are important. Influenza and pneumococcal vaccination is recommended. Treatment of hypoxaemia and hypercapnia reduce the rate of COPD exacerbations, while most interventional bronchoscopic therapies increase exacerbation risk within the first months after the procedure.

\section{Introduction}

Chronic obstructive pulmonary disease (COPD) is the third leading cause of death worldwide [1]. While COPD is a mainly chronic disease, a substantial number of patients suffer from exacerbations, which are defined as an acute worsening of respiratory symptoms requiring a change in treatment. Exacerbations are an important medical and healthcare problem, e.g. it is evident that severe exacerbations of COPD are related to a significantly worse survival outcome [2].

The Global Initiative for Chronic Obstructive Lung Disease (GOLD) 2017 report refined the ABCD assessment tool, to utilise respiratory symptoms and exacerbations alone to assign ABCD categories [3]. It

Previous articles in this series: No. 1: Kondoh Y, Cottin V, Brown KK. Recent lessons learned in the management of acute exacerbation of idiopathic pulmonary fibrosis. Eur Respir Rev 2017; 26: 170050. No. 2: Savale L, Weatherald J, Jäis X, et al. Acute decompensated pulmonary hypertension. Eur Respir Rev 2017; 26: 170092.

Received: Sept 062017 | Accepted after revision: Jan 112018

Provenance: Commissioned article, peer reviewed.

Copyright CERS 2018. ERR articles are open access and distributed under the terms of the Creative Commons Attribution Non-Commercial Licence 4.0. 
is recommended that symptoms and future risk of exacerbation be assessed as a basis for pharmacological management of stable COPD.

This article summarises the current knowledge on risk factors and triggers, treatment and prevention of exacerbations of COPD (figure 1).

\section{Risk factors and triggers}

There are several risk factors and triggers of exacerbations of COPD. Since many patients with COPD have significant comorbidities, the final paragraph in this section focuses on important differential diagnoses that should be taken into account.

\section{Smoking and air pollution}

Tobacco smoke is the major risk factor for developing COPD $[4,5]$. Therefore, smokers should be provided with counselling for smoking cessation. COPD is more common in males than in females [6], but there is an increase in tobacco smoking among females. This is of special importance, because studies have shown that the susceptibility to smoking and frequent exacerbations in COPD is stronger in females than in males $[7,8]$.

The effect of air pollution on COPD exacerbations is still under debate. Some studies have demonstrated that air pollution significantly increases the risk of exacerbations $[9,10]$, while older studies found no relevant correlations. A recent systematic review and meta-analysis showed that short-term exposure to major air pollutants could significantly increase the risk for exacerbations of COPD [11]. In summary, there is a trend towards an association of air pollution with exacerbations.

\section{Severe airflow limitation}

In a prospective study, patients were followed-up for 4 years after the first hospitalisation due to exacerbation of COPD [12]. The highest mortality was seen in the group with severe airflow limitation. In addition, patients in that group had more frequent hospitalisations due to COPD. Data on 2164 patients from the ECLIPSE (Evaluation of COPD Longitudinally to Identify Predictive Surrogate Endpoints) cohort revealed five subgroups using cross-sectional clinical features [13]. The subgroup with most exacerbations of COPD had the second highest mortality within 3 years. Mortality was only slightly higher in the subgroup with many comorbidities and evidence of systemic inflammation.

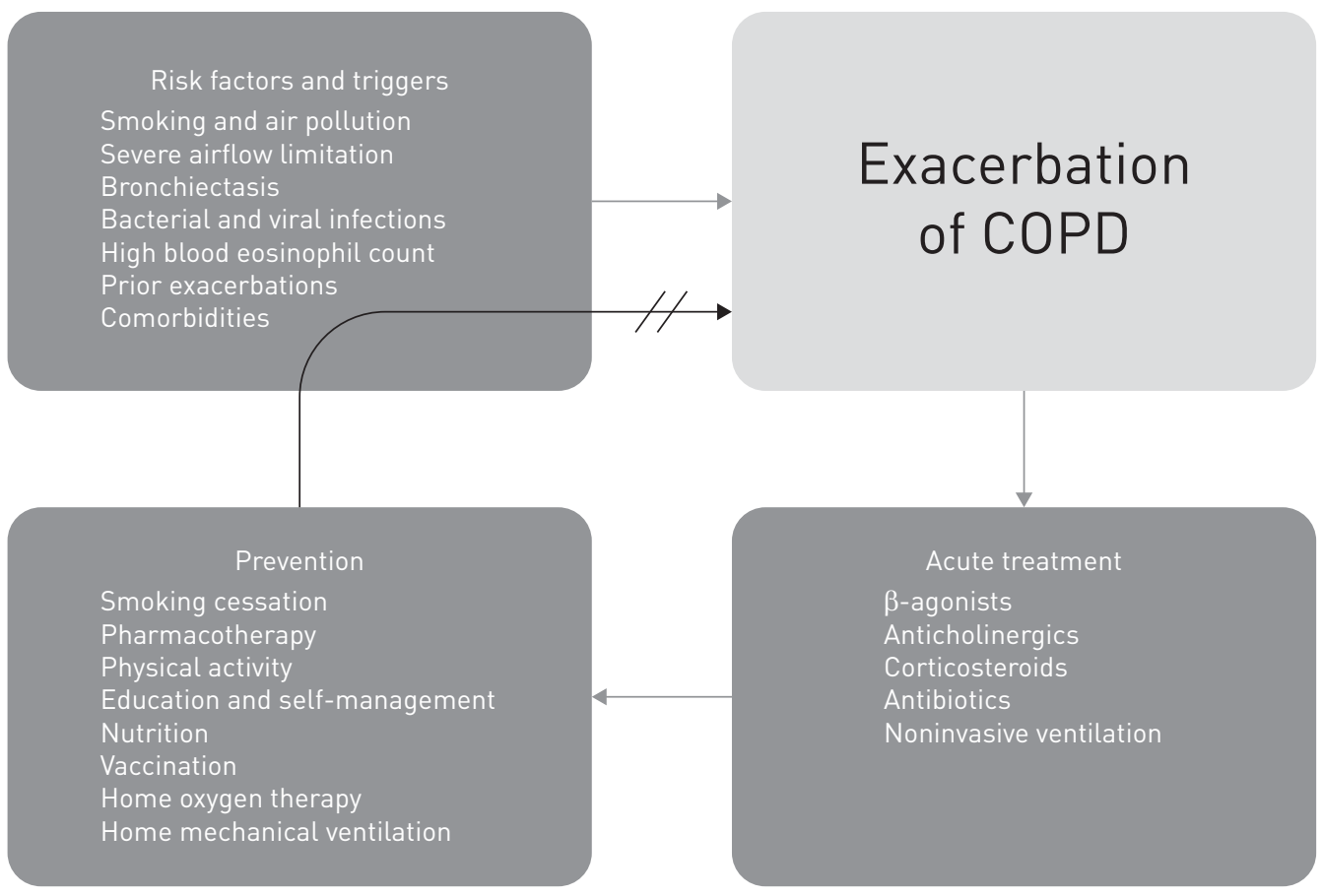

FIGURE 1 Several risk factors and triggers are involved in exacerbations of chronic obstructive pulmonary disease (COPD). In the acute setting, adequate treatment is necessary; then, appropriate measures for prevention of a subsequent exacerbation should be initiated. 


\section{Bronchiectasis}

A meta-analysis of six observational studies demonstrated a correlation between the detection of bronchiectasis in (high-resolution) computed tomography in patients with COPD and the frequency of exacerbations (weighted mean difference 1.54 times in the previous year) [14]. Since these patients with bronchiectasis had more chronic colonisation by pathogenic microorganisms (odds ratio 7.33) and a higher rate of Pseudomonas aeruginosa isolation (odds ratio 3.5), this coexistence is considered a potential mechanism for frequent exacerbations.

\section{Microorganisms}

COPD patients may have evidence of chronic lower respiratory tract colonisation with bacteria, but the detection of bacteria in the sputum of patients with COPD does not mean that in general these patients have a higher risk of exacerbations. Older studies did not find differences between the rates of isolation of bacteria from sputum during stable disease and exacerbation [15]. More recent studies found an association between exacerbation and the isolation of a new strain of a bacterial pathogen [16]. In addition, the reported efficacy of long-term antibiotic treatment with macrolides in reducing exacerbation frequency may suggest that bacteria are relevant for the induction of exacerbations, although this is a matter of debate [17].

Viral infections are an even more important risk factor for exacerbations of COPD. A case-control study found viral respiratory pathogens more often in respiratory specimens of hospitalised patients with exacerbated COPD than in control patients (56\% versus 19\%) [18]. The most common viruses detected were picornaviruses (36\%), followed by influenza A (25\%), respiratory syncytial virus (22\%) and parainfluenza (10\%). A review of 24 studies of viral infections in COPD exacerbations (from 2001 to 2015) showed virus detection rates in respiratory specimens of 22-64\% [19]. The investigation of the impact of seasonality on COPD exacerbation frequency in the TORCH (Towards a Revolution in COPD Health) study showed an almost two-fold increase in the winter months in both the northern and southern regions, while no seasonal pattern occurred in the tropics [20]. The authors suspected increased exposure to viral infections to be a potentially contributing factor.

\section{Biomarkers}

Many potential biomarkers have been tested with the goal of predicting the development of exacerbations. The COPD Foundation Biomarker Qualification Consortium showed that patients with elevated levels of fibrinogen had a nearly two-fold increased risk of death from any cause over 3 years [21]. This led to the United States Food and Drug Administration qualification of plasma fibrinogen as a prognostic biomarker for all-cause mortality and COPD exacerbations. A study published more recently tested $\sim 90$ biomarkers from the two patient cohorts SPIROMICS (Subpopulations and Intermediate Outcomes Measures in COPD Study) and COPDGene (Genetic Epidemiology of COPD) [22]. Although within each cohort a subset of biomarkers was associated with exacerbations, replication across the two cohorts was poor. Fibrinogen was not a predictive biomarker of exacerbation in SPIROMICS nor COPDGene. The only two blood biomarkers predictive of future severe exacerbations were decorin and $\alpha_{2}$-macroglobulin. The authors concluded that these blood biomarkers had only little additive value.

Another widely examined study parameter is the eosinophil count. A high eosinophil count in blood is associated with an increased risk of COPD exacerbations [23]. Accordingly, other studies found associations between treatment with corticosteroids or their withdrawal and the eosinophil count. In patients with high eosinophil counts there were more exacerbations per year: the higher the eosinophil count, the more exacerbations [24]. This increased exacerbation rate could be decreased by an inhaled corticosteroid. A similar result was seen in a post hoc analysis of the WISDOM (Withdrawal of Inhaled Steroids during Optimised Bronchodilator Management) study [25]. Patients with blood eosinophils counts $>300$ cells $\mu \mathrm{L}^{-1}$ had a higher exacerbation rate after complete withdrawal of inhaled corticosteroids. The results of prospective studies with patient stratifcation based on blood eosinophil count must be awaited before eosinophil counts can be recommended for wider use.

\section{Prior exacerbations}

Prior exacerbations of COPD have an impact on the long-term course of the disease. In a study by SuISSA et al. [26], the risk of subsequent severe exacerbation was increased three-fold after the second severe exacerbation and 24-fold after the 10th, relative to the first. Additionally, the median time from one to the next hospitalised exacerbation decreased with the number of previous exacerbations. In the POET-COPD (Prevention of Exacerbations with Tiotropium in COPD) trial, frequent exacerbators had a three-fold increase in mortality [27]. The most important prognostic factor was exacerbation-related hospitalisation. In particular, readmission within 30 days after COPD exacerbation was correlated with an increased risk of mortality [28]. The most important predictor of frequent exacerbations is a history of exacerbations [29]. 
Comorbidities

Most patients with COPD have comorbidities. The five most prevalent comorbidities are hyperglycaemia, atherosclerosis, hypertension, dyslipidaemia and osteoporosis [30]. The importance of the different comorbidities for hospitalisation and mortality has been presented in "comorbidomes" [31, 32]. Psychiatric comorbidities such as anxiety and depression may have a negative impact on exacerbation frequency.

In addition, some comorbidities may mimic an exacerbation of COPD (e.g. decompensated heart failure or ischaemic heart disease).

\section{Treatment of COPD exacerbations}

The goal of treatment is to minimise the negative impact of the current exacerbation. This can be achieved by a number of medical interventions.

\section{$\boldsymbol{\beta}$-agonists and anticholinergics}

Despite the lack of high-quality evidence, there is a consensus that short-acting inhaled $\beta_{2}$-agonists and short-acting anticholinergics are the initial treatment of COPD exacerbations [3, 33]. Before hospital discharge, maintenance therapy with long-acting bronchodilators should be initiated. Based on currently available data, long-acting antimuscarinic antagonists (LAMA) seem to have a greater effect on exacerbation rates than long-acting $\beta_{2}$-agonists (LABA) [34, 35]. Therefore, in the pharmacological treatment algorithm, the GOLD 2017 report [3] recommends starting therapy with a LAMA, in group C patients especially. Patients with further exacerbation(s) should be treated with a LAMA/LABA combination.

\section{Corticosteroids}

Systemic corticosteroids have been used as standard treatment for exacerbations for a long time [36]. They have been shown to improve lung function and oxygenation, to shorten recovery time and duration of hospitalisation and to reduce treatment failures. The REDUCE (Reduction in the Use of Corticosteroids in Exacerbated COPD) randomised clinical trial revealed that 5-day treatment with systemic corticosteroids compared to 14-day treatment had similar rates of re-exacerbation within 6 months of follow-up [37]. Therefore, systemic corticosteroids should not be administered for $>5-7$ days. The recently published European Respiratory Society (ERS)/American Thoracic Society (ATS) guidelines for the management of COPD exacerbations suggest a short course ( $\leqslant 14$ days) of oral corticosteroids for ambulatory patients with an exacerbation of COPD [38]. Even for patients who are hospitalised due to a COPD exacerbation, the guidelines suggest the administration of oral rather than i.v. corticosteroids.

Moreover, a pharmacoepidemiological cohort study came to the conclusion that lower dosage strategies should be encouraged for patients admitted to the intensive care unit (ICU) [39]. The group with lower-dose methylprednisolone had a similar rate of mortality, but was associated with reduced hospital and ICU length of stay as well as reduced hospital cost, length of invasive ventilation, need of insulin therapy and fungal infections.

\section{Antibiotics}

A systematic review of COPD guidelines revealed that criteria for treatment with antibiotics were mainly an increase in respiratory symptoms [40]. The ERS/ATS guidelines for the management of COPD exacerbations suggest the administration of antibiotics for ambulatory patients having a COPD exacerbation [38]. It seems obvious that antibiotics should only be given in patients with presumed bacterial infection. The expectoration of purulent sputum is the clinical parameter that suggests that a relevant bacterial infection is present. To differentiate between chronic colonisation and acute infection, procalcitonin levels can be assessed as a marker for antibiotic treatment $[41,42]$. If the procalcitonin level is elevated, antibiotic treatment should be given. The duration of antibiotic therapy should usually be 5-7 days.

\section{Noninvasive ventilation}

A meta-analysis from 2003 concluded that noninvasive ventilation (NIV) is the first-line intervention in patients with COPD exacerbation in addition to usual medical care [43]. NIV should be used early in the course of disease. The numbers needed to treat to reduce mortality was only 8. At present, NIV is a standard of care in COPD patients with acute respiratory failure $[3,38,44]$.

\section{Prevention of COPD exacerbations}

The primary goal should be to prevent the first exacerbation. If that cannot be achieved, appropriate measures for prevention of a subsequent exacerbation should be initiated [3]. 
Smoking cessation

Smoking cessation is key to prevent further morbidity and mortality in patients with COPD [45]. It has been shown that smoking cessation can slow decline in forced expiratory volume in $1 \mathrm{~s}$ (FEV1) over time in patients with COPD [46].

Although there is some evidence for lower annual exacerbation rates in smokers who switch to electronic cigarettes [47], there is also evidence that electronic cigarettes may have significant pulmonary toxicity [48]. Therefore, some organisations have suggested caution in using electronic cigarettes as a form of nicotine replacement therapy until further data are available [49].

\section{Pharmacotherapy}

Bronchodilation with LABA and/or LAMA is recommended for most COPD patients. Several studies have shown that long-acting bronchodilators reduce the risk of COPD exacerbation [50].

\section{LABA monotherapy}

Bronchodilation with the LABA salmeterol has been shown to reduce the annual rate of COPD exacerbations by $20 \%$, compared with placebo [51]. A reduction in exacerbation rate was also seen with other LABAs [52]. The effect of LABA on exacerbations is irrespective of previous exacerbation history.

\section{LAMA monotherapy}

LAMAs seem to be more effective in preventing exacerbations compared to LABA [34, 35]. Bronchodilation with LAMAs reduce exacerbation rates compared with placebo by $\sim 35 \%$ overall [50]. Therefore, both the GOLD 2017 report and the recently published ERS/ATS guidelines for prevention of COPD favour LAMA monotherapy over LABA monotherapy in patients with a history of exacerbations $[3,53]$.

\section{Inhaled corticosteroids}

While long-term therapy with oral corticosteroids is not recommended, long-term treatment with inhaled corticosteroids (ICS) may be considered for patients with a history of exacerbations (GOLD groups C and D) [3]. ICS therapy should always be combined with long-acting bronchodilators. Nevertheless, long-term use of ICS in patients with COPD is still controversial. The most important adverse effects are increased risks of pneumonia, diabetes and fractures [54-56]. In the WISDOM study, withdrawal of ICS was not associated with an increased risk of exacerbations [57].

Recent studies have recommended using the peripheral blood eosinophil count as a biomarker for directing corticosteroids in exacerbations of COPD [24], as discussed earlier, in the section on biomarkers. In particular, patients with overlap of asthma and COPD and potentially high blood eosinophil counts may benefit from the addition of inhaled corticosteroids to a bronchodilator therapy.

\section{Combination therapies}

With the many available fixed combinations (LABA/ICS and LABA/LAMA) it is easier to escalate therapy. A significant reduction in terms of exacerbation can be achieved by combining a LABA and LAMA compared to both LAMA alone or LABA/ICS $[58,59]$. This further highlights that ICS should only be used thoughtfully.

Most recently, Gross and BARnES [60] summarised the latest developments in upcoming therapies for COPD, including triple inhalers (fixed combinations of LABA/LAMA/ICS). The studies TRILOGY (Single Inhaler Triple Therapy versus Inhaled Corticosteroid plus Long-acting $\beta$-Agonist Therapy for Chronic Obstructive Pulmonary Disease) and TRINITY (Single Inhaler Extrafine Triple Therapy versus Long-Acting Muscarinic Antagonist Therapy for Chronic Obstructive Pulmonary Disease) both showed a reduction of exacerbations with triple therapy compared to LABA/ICS [61, 62]. There are no data yet on triple therapy versus LABA/LAMA, but it is expected that two large trials will publish data later this year.

\section{Phosphodiesterase-4 inhibitor}

Both the GOLD 2017 report and the ERS/ATS guidelines for prevention of COPD recommend a phosphodiesterase-4 inhibitor (roflumilast) as a treatment option for patients with COPD who have severe and very severe airflow limitation, chronic bronchitis and a high risk of exacerbations [3, 53]. In a Cochrane review of 29 randomised controlled trials (15 trials with roflumilast and 14 trials with cilomilast), treatment with roflumilast compared with placebo was associated with a reduced likelihood of COPD exacerbation (odds ratio (OR) 0.77, 95\% CI 0.71-0.83) [63]. The most common adverse effects are gastrointestinal in nature. Some concerns have been raised about psychiatric adverse effects (insomnia, anxiety, depression and suicidal behaviour). 
Prophylactic antibiotics

In patients with cystic fibrosis, there is a well-established indication for the long-term use of inhaled antibiotics to prevent exacerbation [64]. Since bacterial infections can trigger exacerbations in patients, long-term antibiotic treatment has been considered in COPD, too. A Cochrane review of seven randomised controlled trials in patients with COPD showed a clinically significant benefit with use of continuous prophylactic antibiotics compared with placebo, while the benefit of intermittent antibiotic prophylaxis remained uncertain [65]. With continuous prophylactic antibiotics both the number of patients experiencing an exacerbation (OR 0.55, 95\% CI 0.39-0.77) as well as the frequency of exacerbations (rate ratio $0.73,95 \%$ CI $0.58-0.91$ ) was reduced, compared with placebo.

Most evidence is available for macrolide antibiotics, while there are few data on fluoroquinolones. The GOLD 2017 report states that macrolides can be considered in former smokers who have exacerbations despite appropriate therapy [3]. The ERS/ATS guidelines for prevention of COPD exacerbations suggest treatment with macrolide antibiotics for patients with moderate to very severe airflow obstruction and exacerbations despite optimal inhaled therapy [53]. Nevertheless, potential risks such as antibiotic resistance and specific adverse effects need to be considered when treating patients with prophylactic antibiotics [66].

Mucolytics

A Cochrane review of 34 studies showed that a mucolytic therapy in patients with COPD increases the likelihood of being exacerbation free [67], compared with placebo. The number needed to treat (to keep an additional patient free from exacerbations for an average of 10 months) was eight. However, due to much heterogeneity between the studies, these data should be interpreted with caution. Therefore, the GOLD 2017 report recommends the use of mucolytics only in selected patients. The recently published ERS/ATS guidelines for prevention of COPD exacerbations [53] suggest treatment with an oral mucolytic agent for patients with moderate to severe airflow obstruction and exacerbations despite optimal inhaled therapy.

\section{Monoclonal antibodies}

In a recently published study on patients with COPD with an eosinophilic phenotype, mepolizumab (a monoclonal antibody directed against interleukin-5) was associated with a lower annual rate of moderate to severe exacerbations compared to placebo [68]. This was especially true for patients with higher blood eosinophil counts at screening. While there are no data yet to generally recommend this treatment, it suggests that eosinophilic airway inflammation may contribute to COPD exacerbations.

\section{Physical activity and pulmonary rehabilitation}

Activity is the strongest predictor of mortality in patients with COPD $[69,70]$, i.e. patients with low levels of physical activity have a higher risk of mortality. While a Cochrane review showed high-quality evidence for pulmonary rehabilitation versus controls to improve health-related quality of life and exercise capacity, the results for reducing hospital readmissions were heterogeneous and the evidence of moderate quality (pooled OR 0.44, 95\% CI 0.21-0.91) [71]. Nevertheless, beside smoking cessation and pharmacotherapy, patients should be especially encouraged to increase their physical activity.

\section{Education and self-management}

The current GOLD 2017 report recommends better education and self-management of patients [3]. A Cochrane review on self-management interventions for patients with COPD showed significant advantages in terms of respiratory-related hospital admissions and dyspnoea [72].

\section{Nutrition}

While nutritional status is important for general outcome of COPD, there are no reliable studies on nutrition and prevention of COPD exacerbations [73]. A Cochrane review showed only slight improvements of nutritional supplementation in COPD [74].

\section{Vaccination}

Current guidelines recommend influenza and pneumococcal vaccination for patients with COPD [3]. Two systematic Cochrane reviews showed a reduction in exacerbations in COPD patients for both vaccinations versus control $[75,76]$.

\section{Treatment of hypoxaemia and hypercapnia}

Two trials undertaken in the 1970s showed a decrease in mortality in patients with COPD and severe resting hypoxaemia when receiving home oxygen therapy (HOT) compared to nocturnal oxygen therapy or control $[77,78]$. In a more recent study from the Long-Term Oxygen Treatment Trial Research Group, patients with stable COPD and resting or exercise-induced moderate desaturation had no benefit of HOT versus the no supplemental oxygen group in terms of mortality, exacerbations or functional status [79]. 
The widely discussed study by KöHNLEIN et al. [80] showed a dramatic improvement of 1-year mortality ( $12 \%$ versus $33 \%)$ in patients with hypercapnic, stable COPD when home mechanical ventilation (HMV) was targeted to reduce hypercapnia. Most recently, the first results from the HoT-HMV trial were published in a late-breaking abstract [81]. 116 patients on HOT with persistent hypercapnia 2-4 weeks after COPD exacerbations were randomised to either additional HMV or HOT alone. The addition of HMV to HOT improved the admission-free survival (median 4.3 months versus 1.4 months). Although both studies may be impacted by selection bias, the data emphasise the need for close monitoring of hypercapnia after hospital discharge from severe exacerbation of COPD.

\section{Intervention bronchoscopy}

Several interventions have been tried to reduce emphysema-associated lung hyperinflation in patients with COPD. For most patients, there were only modest treatment effects. In contrast, the rate of exacerbations was even increased within the first 3 months after the intervention. Endobronchial coil treatment resulted in a nonsignificant increase of risk for COPD exacerbation compared to usual care alone (27.7\% versus $20.4 \%, \mathrm{p}=0.15)$ [82]. For endobronchial valve therapy $(7.9 \%$ versus $1.1 \%, \mathrm{p}=0.03)$ and thermal vapour ablation (24\% versus $4 \%$ ) there was a significant increase of exacerbation risk compared to control [83, 84]. 9-12 months after the interventions the exacerbation risk was similar to that of the control groups.

\section{Conclusions}

COPD is and will remain a significant health burden. The prevention of exacerbations is one of the most important treatment goals. To achieve that goal, patient education and smoking cessation programmes as well as patient-tailored pharmacological and nonpharmacological treatments are mandatory.

Author contributions: All authors contributed to the content of this manuscript and approved the final version to be submitted.

Conflict of interest: C. Viniol has received personal fees from Novartis and Mundipharma, outside the submitted work. C.F. Vogelmeier has received personal fees from Almirall, Cipla, Berlin Chemie/Menarini, CSL Behring and Teva. He has received grants and personal fees from AstraZeneca, Boehringer Ingelheim, Chiesi, GlaxoSmithKline, Grifols, Mundipharma, Novartis and Takeda. He has received grants from the German Federal Ministry of Education and Research (BMBF) Competence Network Asthma and COPD (ASCONET), Bayer Schering Pharma AG, MSD and Pfizer, outside the submitted work.

\section{References}

1 Lozano R, Naghavi M, Foreman K, et al. Global and regional mortality from 235 causes of death for 20 age groups in 1990 and 2010: a systematic analysis for the Global Burden of Disease Study 2010. Lancet 2012; 380: 2095-2128.

2 Soler-Cataluña JJ, Martínez-García MA, Román Sánchez P, et al. Severe acute exacerbations and mortality in patients with chronic obstructive pulmonary disease. Thorax 2005; 60: 925-931.

3 Vogelmeier CF, Criner GJ, Martinez FJ, et al. Global Strategy for the Diagnosis, Management, and Prevention of Chronic Obstructive Lung Disease 2017 Report: GOLD executive summary. Eur Respir J 2017; 49: 1700214.

4 Mannino DM, Buist AS. Global burden of COPD: risk factors, prevalence, and future trends. Lancet 2007; 370: 765-773.

5 Lopez AD, Mathers CD, Ezzati M, et al. Global Burden of Disease and Risk Factors. Washington, DC, World Bank and Oxford University Press, 2012.

6 Adeloye D, Chua S, Lee C, et al. Global and regional estimates of COPD prevalence: systematic review and meta-analysis. J Glob Health 2015; 5: 020415.

7 Sundh J, Johansson G, Larsson K, et al. The phenotype of concurrent chronic bronchitis and frequent exacerbations in patients with severe COPD attending Swedish secondary care units. Int J Chron Obstruct Pulmon Dis 2015; 10: 2327-2334.

8 Sørheim I-C, Johannessen A, Gulsvik A, et al. Gender differences in COPD: are women more susceptible to smoking effects than men? Thorax 2010; 65: 480-485.

9 DeVries R, Kriebel D, Sama S. Low level air pollution and exacerbation of existing COPD: a case crossover analysis. Environ Health 2016; 15: 98.

10 Neuberger M, Moshammer H, Rabczenko D. Acute and subacute effects of urban air pollution on cardiopulmonary emergencies and mortality: time series studies in Austrian cities. Int J Environ Res Public Health 2013; 10: 4728-4751.

11 Li J, Sun S, Tang R, et al. Major air pollutants and risk of COPD exacerbations: a systematic review and meta-analysis. Int J Chron Obstruct Pulmon Dis 2016; 11: 3079-3091.

12 Garcia-Aymerich J, Gómez FP, Benet M, et al. Identification and prospective validation of clinically relevant chronic obstructive pulmonary disease (COPD) subtypes. Thorax 2011; 66: 430-437.

13 Rennard SI, Locantore N, Delafont B, et al. Identification of five chronic obstructive pulmonary disease subgroups with different prognoses in the ECLIPSE cohort using cluster analysis. Ann Am Thorac Soc 2015; 12: 303-312.

$14 \mathrm{Ni}$ Y, Shi G, Yu Y, et al. Clinical characteristics of patients with chronic obstructive pulmonary disease with comorbid bronchiectasis: a systemic review and meta-analysis. Int J Chron Obstruct Pulmon Dis 2015; 10: 1465-1475.

15 Gump DW, Phillips CA, Forsyth BR, et al. Role of infection in chronic bronchitis. Am Rev Respir Dis 1976; 113: 465-474.

16 Sethi S, Evans N, Grant BJB, et al. New strains of bacteria and exacerbations of chronic obstructive pulmonary disease. $N$ Engl J Med 2002; 347: 465-471.

17 Albert RK, Connett J, Bailey WC, et al. Azithromycin for prevention of exacerbations of COPD. N Engl J Med 2011; 365: 689-698. 
18 Rohde G, Wiethege A, Borg I, et al. Respiratory viruses in exacerbations of chronic obstructive pulmonary disease requiring hospitalisation: a case-control study. Thorax 2003; 58: 37-42.

19 Hewitt R, Farne H, Ritchie A, et al. The role of viral infections in exacerbations of chronic obstructive pulmonary disease and asthma. Ther Adv Respir Dis 2016; 10: 158-174.

20 Jenkins CR, Celli B, Anderson JA, et al. Seasonality and determinants of moderate and severe COPD exacerbations in the TORCH study. Eur Respir J 2012; 39: 38-45.

21 Miller BE, Tal-Singer R, Rennard SI, et al. Plasma fibrinogen qualification as a drug development tool in chronic obstructive pulmonary disease. Perspective of the Chronic Obstructive Pulmonary Disease Biomarker Qualification Consortium. Am J Respir Crit Care Med 2016; 193: 607-613.

22 Keene JD, Jacobson S, Kechris K, et al. Biomarkers predictive of exacerbations in the SPIROMICS and COPDGene cohorts. Am J Respir Crit Care Med 2017; 195: 473-481.

23 Bafadhel M, McKenna S, Terry S, et al. Blood eosinophils to direct corticosteroid treatment of exacerbations of chronic obstructive pulmonary disease: a randomized placebo-controlled trial. Am J Respir Crit Care Med 2012; 186: 48-55.

24 Pascoe S, Locantore N, Dransfield MT, et al. Blood eosinophil counts, exacerbations, and response to the addition of inhaled fluticasone furoate to vilanterol in patients with chronic obstructive pulmonary disease: a secondary analysis of data from two parallel randomised controlled trials. Lancet Respir Med 2015; 3: 435-442.

25 Watz H, Tetzlaff K, Wouters EFM, et al. Blood eosinophil count and exacerbations in severe chronic obstructive pulmonary disease after withdrawal of inhaled corticosteroids: a post-hoc analysis of the WISDOM trial. Lancet Respir Med 2016; 4: 390-398.

26 Suissa S, Dell'Aniello S, Ernst P. Long-term natural history of chronic obstructive pulmonary disease: severe exacerbations and mortality. Thorax 2012; 67: 957-963.

27 Beeh KM, Glaab T, Stowasser S, et al. Characterisation of exacerbation risk and exacerbator phenotypes in the POET-COPD trial. Respir Res 2013; 14: 116.

28 Guerrero M, Crisafulli E, Liapikou A, et al. Readmission for acute exacerbation within 30 days of discharge is associated with a subsequent progressive increase in mortality risk in COPD patients: a long-term observational study. PLoS One 2016; 11: e0150737.

29 Hurst JR, Vestbo J, Anzueto A, et al. Susceptibility to exacerbation in chronic obstructive pulmonary disease. N Engl J Med 2010; 363: 1128-1138.

30 Vanfleteren LEGW, Spruit MA, Groenen M, et al. Clusters of comorbidities based on validated objective measurements and systemic inflammation in patients with chronic obstructive pulmonary disease. Am $\mathrm{J}$ Respir Crit Care Med 2013; 187: 728-735.

31 Divo M, Cote C, de Torres JP, et al. Comorbidities and risk of mortality in patients with chronic obstructive pulmonary disease. Am J Respir Crit Care Med 2012; 186: 155-161.

32 van Boven JFM, Román-Rodríguez M, Palmer JF, et al. Comorbidome, pattern, and impact of asthma-COPD overlap syndrome in real life. Chest 2016; 149: 1011-1020.

33 Celli BR, MacNee W, Agustí A, et al. Standards for the diagnosis and treatment of patients with COPD: a summary of the ATS/ERS position paper. Eur Respir J 2004; 23: 932-946.

34 Vogelmeier C, Hederer B, Glaab T, et al. Tiotropium versus salmeterol for the prevention of exacerbations of COPD. N Engl J Med 2011; 364: 1093-1103.

35 7Decramer ML, Chapman KR, Dahl R, et al. Once-daily indacaterol versus tiotropium for patients with severe chronic obstructive pulmonary disease (INVIGORATE): a randomised, blinded, parallel-group study. Lancet Respir Med 2013; 1: 524-533.

36 Niewoehner DE, Erbland ML, Deupree RH, et al. Effect of systemic glucocorticoids on exacerbations of chronic obstructive pulmonary disease. N Engl J Med 1999; 340: 1941-1947.

37 Leuppi JD, Schuetz P, Bingisser R, et al. Short-term vs conventional glucocorticoid therapy in acute exacerbations of chronic obstructive pulmonary disease: the REDUCE randomized clinical trial. JAMA 2013; 309: 2223-2231.

38 Wedzicha JA, Miravitlles M, Hurst JR, et al. Management of COPD exacerbations: a European Respiratory Society/American Thoracic Society guideline. Eur Respir J 2017; 49: 1600791.

39 Kiser TH, Allen RR, Valuck RJ, et al. Outcomes associated with corticosteroid dosage in critically ill patients with acute exacerbations of chronic obstructive pulmonary disease. Am J Respir Crit Care Med 2014; 189: $1052-1064$.

40 Laue J, Reierth E, Melbye H. When should acute exacerbations of COPD be treated with systemic corticosteroids and antibiotics in primary care: a systematic review of current COPD guidelines. NPJ Prim Care Respir Med 2015; 25: 15002.

41 Niewoehner DE. Procalcitonin level-guided treatment reduced antibiotic use in exacerbations of COPD. ACP $J$ Club 2007; 146: 57.

42 Stolz D, Christ-Crain M, Bingisser R, et al. Antibiotic treatment of exacerbations of COPD: a randomized, controlled trial comparing procalcitonin-guidance with standard therapy. Chest 2007; 131: 9-19.

43 Lightowler JV, Wedzicha JA, Elliott MW, et al. Non-invasive positive pressure ventilation to treat respiratory failure resulting from exacerbations of chronic obstructive pulmonary disease: Cochrane systematic review and meta-analysis. BMJ 2003; 326: 185.

44 Westhoff M, Schönhofer B, Neumann P, et al. Nicht-invasive Beatmung als Therapie der akuten respiratorischen Insuffizienz. [Noninvasive mechanical ventilation in acute respiratory failure.] Pneumologie 2015; 69: 719-756.

45 Scanlon PD, Connett JE, Waller LA, et al. Smoking cessation and lung function in mild-to-moderate chronic obstructive pulmonary disease. The Lung Health Study. Am J Respir Crit Care Med 2000; 161: 381-390.

46 Anthonisen NR, Connett JE, Kiley JP, et al. Effects of smoking intervention and the use of an inhaled anticholinergic bronchodilator on the rate of decline of FEV1. The Lung Health Study. JAMA 1994; 272: 1497-1505.

47 Polosa R, Morjaria JB, Caponnetto P, et al. Evidence for harm reduction in COPD smokers who switch to electronic cigarettes. Respir Res 2016; 17: 166.

48 Chun LF, Moazed F, Calfee CS, et al. Pulmonary toxicity of e-cigarettes. Am J Physiol Lung Cell Mol Physiol 2017; 313: L193-L206.

49 Schraufnagel DE, Blasi F, Drummond MB, et al. Electronic cigarettes. A position statement of the Forum of International Respiratory Societies. Am J Respir Crit Care Med 2014; 190: 611-618.

50 Miravitlles M, D'Urzo A, Singh D, et al. Pharmacological strategies to reduce exacerbation risk in COPD: a narrative review. Respir Res 2016; 17: 112 
51 Calverley P, Pauwels R, Vestbo J, et al. Combined salmeterol and fluticasone in the treatment of chronic obstructive pulmonary disease: a randomised controlled trial. Lancet 2003; 361: 449-456.

52 Wedzicha JA, Buhl R, Lawrence D, et al. Monotherapy with indacaterol once daily reduces the rate of exacerbations in patients with moderate-to-severe COPD: post-hoc pooled analysis of 6 months data from three large phase III trials. Respir Med 2015; 109: 105-111.

53 Wedzicha JA, Calverley PMA, Albert RK, et al. Prevention of COPD exacerbations: a European Respiratory Society/American Thoracic Society guideline. Eur Respir J 2017; 50: 1602265.

54 DiSantostefano RL, Sampson T, van Le H, et al. Risk of pneumonia with inhaled corticosteroid versus long-acting bronchodilator regimens in chronic obstructive pulmonary disease: a new-user cohort study. PLoS One 2014; 9: e97149.

55 Suissa S, Kezouh A, Ernst P. Inhaled corticosteroids and the risks of diabetes onset and progression. Am J Med 2010; 123: 1001-1006.

56 Loke YK, Cavallazzi R, Singh S. Risk of fractures with inhaled corticosteroids in COPD: systematic review and meta-analysis of randomised controlled trials and observational studies. Thorax 2011; 66: 699-708.

57 Magnussen H, Disse B, Rodriguez-Roisin R, et al. Withdrawal of inhaled glucocorticoids and exacerbations of COPD. N Engl J Med 2014; 371: 1285-1294.

58 Wedzicha JA, Banerji D, Vogelmeier CF. Indacaterol-glycopyrronium for COPD. N Engl J Med 2016; 375: 899-900.

59 Zhong N, Wang C, Zhou X, et al. LANTERN: a randomized study of QVA149 versus salmeterol/fluticasone combination in patients with COPD. Int J Chron Obstruct Pulmon Dis 2015; 10: 1015-1026.

60 Gross NJ, Barnes PJ. New therapies for asthma and chronic obstructive pulmonary disease. Am J Respir Crit Care Med 2017; 195: 159-166.

61 Singh D, Papi A, Corradi M, et al. Single inhaler triple therapy versus inhaled corticosteroid plus long-acting $\beta_{2}$-agonist therapy for chronic obstructive pulmonary disease (TRILOGY): a double-blind, parallel group, randomised controlled trial. Lancet 2016; 388: 963-973.

62 Vestbo J, Papi A, Corradi M, et al. Single inhaler extrafine triple therapy versus long-acting muscarinic antagonist therapy for chronic obstructive pulmonary disease (TRINITY): a double-blind, parallel group, randomised controlled trial. Lancet 2017; 389: 1919-1929.

63 Chong J, Leung B, Poole P. Phosphodiesterase 4 inhibitors for chronic obstructive pulmonary disease. Cochrane Database Syst Rev 2013; 11: CD002309.

64 Ramsey BW, Pepe MS, Quan JM, et al. Intermittent administration of inhaled tobramycin in patients with cystic fibrosis. $N$ Engl J Med 1999; 340: 23-30.

65 Herath SC, Poole P. Prophylactic antibiotic therapy for chronic obstructive pulmonary disease (COPD). Cochrane Database Syst Rev 2013; 11: CD009764.

66 Wilson R, Sethi S, Anzueto A, et al. Antibiotics for treatment and prevention of exacerbations of chronic obstructive pulmonary disease. J Infect 2013; 67: 497-515.

67 Poole P, Chong J, Cates CJ. Mucolytic agents versus placebo for chronic bronchitis or chronic obstructive pulmonary disease. Cochrane Database Syst Rev 2015; 7: CD001287.

68 Pavord ID, Chanez P, Criner GJ, et al. Mepolizumab for eosinophilic chronic obstructive pulmonary disease. N Engl J Med 2017; 377: 1613-1629.

69 Esteban C, Garcia-Gutierrez S, Legarreta MJ, et al. One-year mortality in COPD after an exacerbation: the effect of physical activity changes during the event. COPD 2016; 13: 718-725.

70 Waschki B, Kirsten A, Holz O, et al. Physical activity is the strongest predictor of all-cause mortality in patients with COPD: a prospective cohort study. Chest 2011; 140: 331-342.

71 Puhan MA, Gimeno-Santos E, Cates CJ, et al. Pulmonary rehabilitation following exacerbations of chronic obstructive pulmonary disease. Cochrane Database Syst Rev 2016; 12: CD005305.

72 Zwerink M, Brusse-Keizer M, van der Valk PDLPM, et al. Self management for patients with chronic obstructive pulmonary disease. Cochrane Database Syst Rev 2014; 3: CD002990.

73 Schols AM, Ferreira IM, Franssen FM, et al. Nutritional assessment and therapy in COPD: a European Respiratory Society statement. Eur Respir J 2014; 44: 1504-1520.

74 Ferreira IM, Brooks D, White J, et al. Nutritional supplementation for stable chronic obstructive pulmonary disease. Cochrane Database Syst Rev 2012; 12: CD000998.

75 Poole PJ, Chacko E, Wood-Baker RWB, et al. Influenza vaccine for patients with chronic obstructive pulmonary disease. Cochrane Database Syst Rev 2006; 1: CD002733.

76 Walters JA, Tang JNQ, Poole P, et al. Pneumococcal vaccines for preventing pneumonia in chronic obstructive pulmonary disease. Cochrane Database Syst Rev 2017; 1: CD001390.

77 Nocturnal Oxygen Therapy Trial Group. Continuous or nocturnal oxygen therapy in hypoxemic chronic obstructive lung disease: a clinical trial. Ann Intern Med 1980; 93: 391-398.

78 Long term domiciliary oxygen therapy in chronic hypoxic cor pulmonale complicating chronic bronchitis and emphysema. Report of the Medical Research Council Working Party. Lancet 1981; 1: 681-686.

79 Albert RK, Au DH, Blackford AL, et al. A randomized trial of long-term oxygen for COPD with moderate desaturation. $N$ Engl J Med 2016; 375: 1617-1627.

80 Köhnlein T, Windisch W, Köhler D, et al. Non-invasive positive pressure ventilation for the treatment of severe stable chronic obstructive pulmonary disease: a prospective, multicentre, randomised, controlled clinical trial. Lancet Respir Med 2014; 2: 698-705.

81 Murphy P, Arbane G, Bourke S, et al. Late-breaking abstract: Improving admission free survival with home mechanical ventilation (HMV) and home oxygen therapy (HOT) following life threatening COPD exacerbations: HoT-HMV UK Trial NCT00990132. Eur Respir J 2016; 48: OA3527.

82 Sciurba FC, Criner GJ, Strange C, et al. Effect of endobronchial coils $v s$ usual care on exercise tolerance in patients with severe emphysema: the RENEW randomized clinical trial. JAMA 2016; 315: 2178-2189.

83 Sciurba FC, Ernst A, Herth FJF, et al. A randomized study of endobronchial valves for advanced emphysema. N Engl J Med 2010; 363: 1233-1244

84 Herth FJF, Valipour A, Shah PL, et al. Segmental volume reduction using thermal vapour ablation in patients with severe emphysema: 6-month results of the multicentre, parallel-group, open-label, randomised controlled STEP-UP trial. Lancet Respir Med 2016; 4: 185-193. 